\title{
A Practical Approach to Interpretation of Dual-Energy X-ray Absorptiometry (DXA) for Assessment of Bone Density
}

\author{
Robert H. Choplin • Leon Lenchik • \\ Scott Wuertzer
}

Published online: 2 April 2014

(c) Springer Science+Business Media New York 2014

\begin{abstract}
Osteoporosis is an extremely common disorder that may result in fractures in several locations. Hip fractures associated with osteoporosis can result in mortality. The defining characteristic of osteoporosis is reduced bone mineral density as identified by dual energy X-ray absorptiometry (DXA). Depending on specific factors, related to the clinical status of the patient or technical aspects of the test itself, interpretation of a DXA examination ranges from straightforward to complicated. We present an approach to evaluation of these factors and production of a clinically relevant report. In this approach, initial screening examinations are regarded as straightforward, follow-up examinations are mildly complex, and examinations that require recalculation of data are complex.
\end{abstract}

Keywords Osteoporosis - Osteopenia $\cdot$ Dual energy $\mathrm{X}$-ray absorptiometry (DXA) $\cdot T$-Score $\cdot Z$-Score . Bone mineral density

This article is part of the Topical Collection on Osteoporosis Imaging.

R. H. Choplin $(\bowtie)$

Department of Radiology, Indiana University School of Medicine, UH0279, 500N. University Blvd, Indianapolis, IN 46202-5253, USA

e-mail: rchoplin@iupui.edu

\section{Lenchik $\cdot$ S. Wuertzer}

Department of Radiology, Wake Forest University School of Medicine, Medical Center Boulevard, Winston-Salem, NC 27157-1088, USA

e-mail: 1lenchik@wakehealth.edu

S. Wuertzer

e-mail: swuertze@wakehealth.edu

\section{Introduction}

Osteoporosis is a systemic yet regionally heterogeneous disease that affects different regions of the skeleton with different severity. Because of this variability, diagnosis and treatment of osteoporosis can be confusing. The disorder is extremely common. In the United States, there are at least 1.5 million osteoporotic fractures every year [1]. Although most patients are women older than 50 years, men also commonly develop osteoporosis. The primary complication of osteoporosis is fractures occurring after minimum trauma. These fractures are referred to as fragility fractures-ones that occur as a result of a force equal to or less than that caused by a fall from standing height [2]. The proximal femur, the vertebral bodies, the distal radius, and the proximal humerus are the most common sites of fracture and thus the most studied. Hip fractures are associated with increased shortterm mortality and high morbidity [3]. Hip, vertebral, and radius fractures increase the risk of future fractures.

A decrease in bone mineral and modification of bone structure is a common part of aging. The densitometric definition of osteoporosis was first established by consensus of a panel convened by the World Health Organization (WHO) in 1994. [4] This definition uses the bone mineral density (BMD) measured by use of dual-energy X-ray absorptiometry (DXA) as the feature defining the disease.

During a DXA examination, a patient is irradiated with an X-ray beam of two different energies, which enables bone attenuation to be separated from soft tissue attenuation. It is extremely important that facilities performing DXA examinations recognize that the main output of this test is quantitative. A quality-control program must be implemented and followed to assure clinicians and patients that the information obtained falls within accepted ranges for precision and accuracy. 
Depending on specific factors, related to the clinical status of the patient or technical aspects of the test itself, interpretation of DXA examinations ranges from straightforward to complicated. The most important aspect of DXA interpretation is estimating a patient's risk of developing an osteoporosis-related fracture. The DXA information includes the BMD, $T$-score, and $Z$-score. The $T$-score enables categorization of patients into one of three diagnoses: normal, low bone mineral density, or osteoporosis. The patient's fracture risk is usually estimated by use of the FRAX ${ }^{\circledR}$ model, which estimates the patient's hip fracture risk for the next 10 years [5]. We describe below an approach to evaluation of these factors and production of clinically relevant DXA reports. The approach includes division of examinations into straightforward, mildly complex, and complex. In this approach, initial screening examinations are regarded as straightforward, follow-up examinations as mildly complex, and examinations that require recalculation of data as complex.

\section{The Straightforward Examination}

\section{Preliminaries}

When a patient is scheduled for the examination, s/he should be told to wear comfortable clothing that can be easily exchanged for a gown and to avoid any jewelry that cannot be easily removed. The examination should not be scheduled close to a nuclear medicine scan where emitted radiation could interfere with accurate BMD measurement.

\section{Provision of Patient History}

To provide the most clinically useful DXA interpretation, the context for the patient must be known. If information is not available from an electronic medical record, a history sheet or questionnaire should be completed by the patient and confirmed by discussion with the technician or the physician. Because estimation of fracture risk is most commonly performed by use of the FRAX $^{\circledR}$ calculator, a history sheet should include, at least, the questions used by FRAX $^{\circledR}$, i.e.: age, sex, weight, height, history of previous fracture (any location), parental history of hip fracture, current smoker, glucocorticoid usage, history of rheumatoid arthritis, history of secondary osteoporosis, and alcohol use. The considerations for secondary osteoporosis include: type I (insulin dependent) diabetes, osteogenesis imperfecta in adults, untreated long-standing hyperthyroidism, hypogonadism or premature menopause ( $<45$ years), chronic malnutrition or malabsorption, and chronic liver disease. The FRAX ${ }^{\circledR}$ calculator is applicable for patients from age 40-90 years. Many DXA scanners manufactured after 2008 incorporate the FRAX $^{\circledR}$ calculator in their software. The FRAX $^{\circledR}$ calculator can also be accessed as a mobile telephone app and online at https:// www.shef.ac.uk/FRAX/tool.aspx.

\section{The Test Components}

A DXA examination most commonly includes a scan of the lumbar spine and one hip. The lumbar spine is usually scanned first (Fig. 1). The patient is then repositioned and the hip is scanned (Fig. 2). As the scan is being acquired
Fig. 1 DXA of the lumbar spine. The lower extremities are elevated and supported with the knees flexed. This positioning reduces the normal lordosis of the spine and enables more consistent positioning of the regions of interest. The spine should be aligned with the center of the table. The table has a centerline drawn on the support surface (visible in Fig. 3)

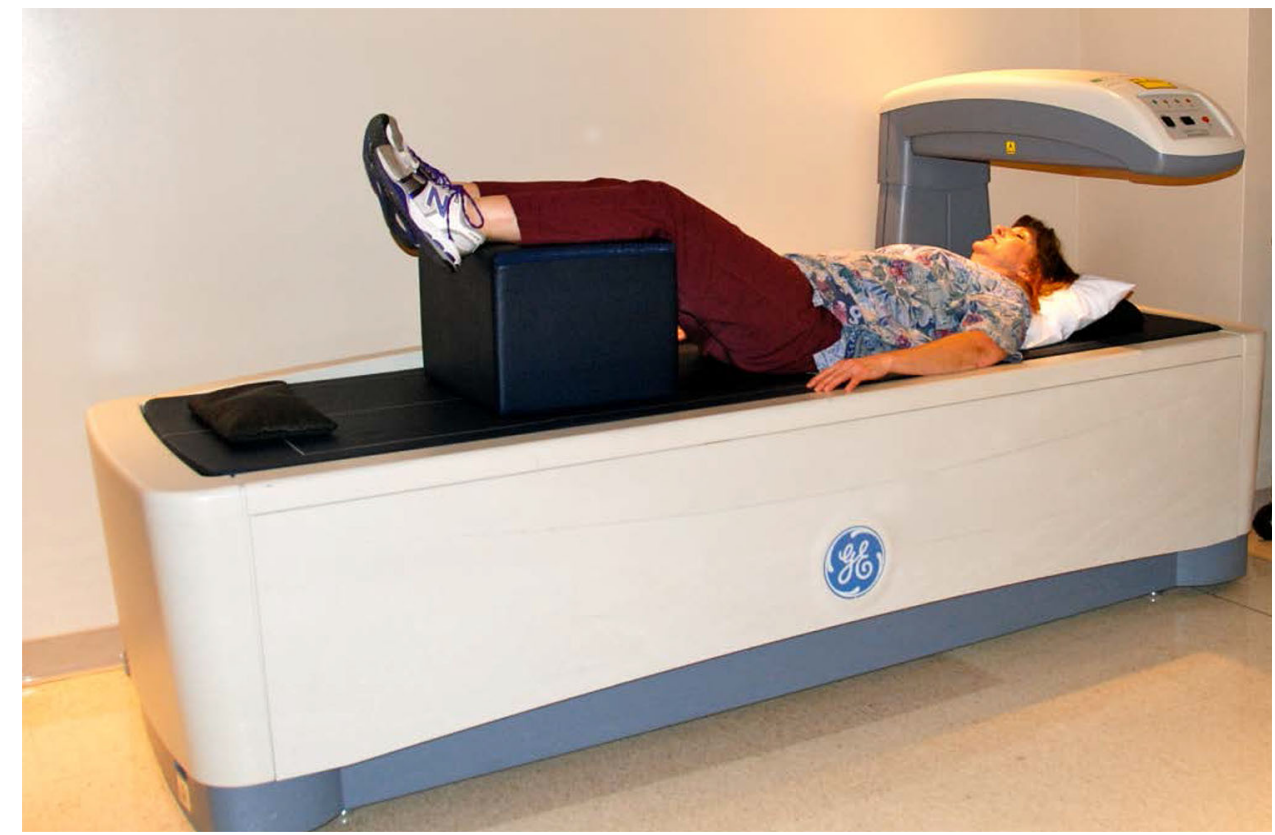


Fig. 2 DXA of the hip. The patient is positioned supine on the scanning table with the lower extremities in internal rotation, to obtain a more enface projection of the femoral neck. All manufacturers provide a positioning aid to help maintain this position

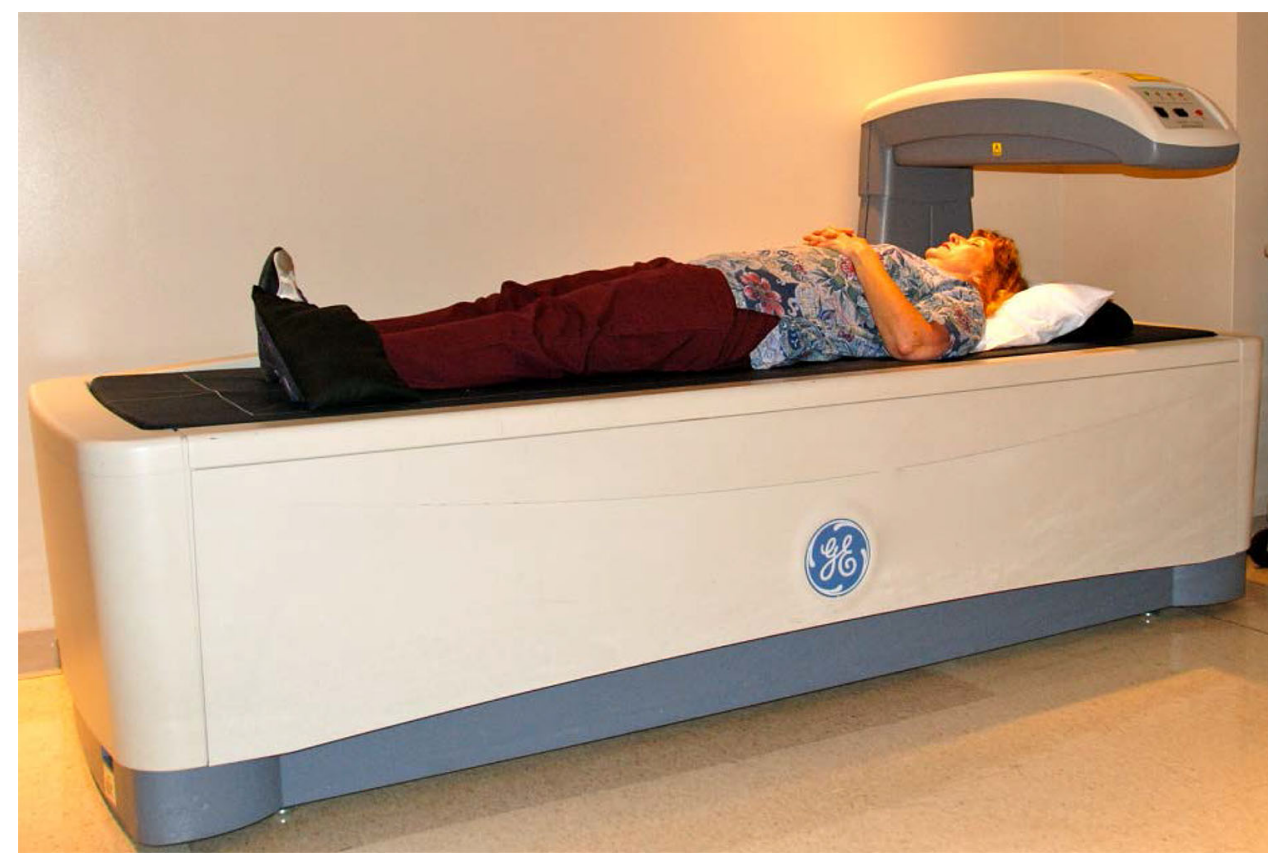

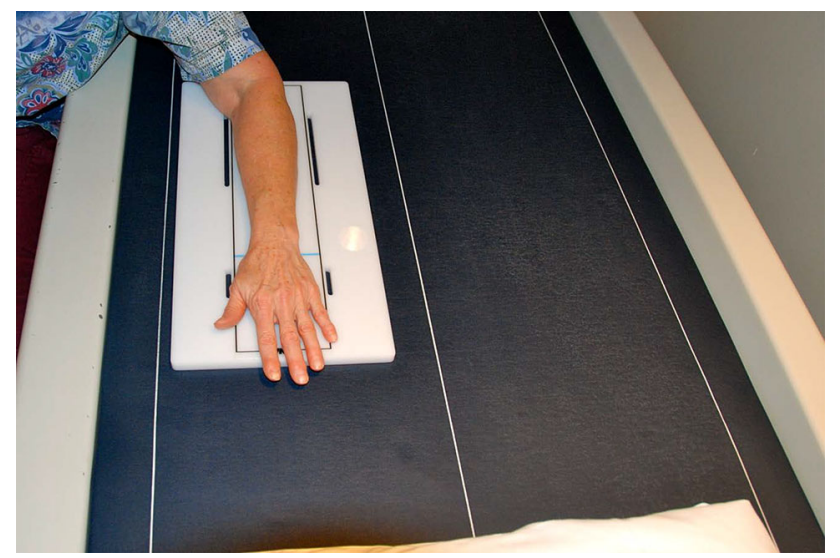

Fig. 3 DXA of the forearm. The patient sits in a chair next to the scanning table with the forearm positioned parallel to the centerline

the technician should view the scan image to confirm patient positioning is correct. The scan takes approximately $10 \mathrm{~min}$ for an uncomplicated ambulatory patient. If one of the regions scanned contains artifacts, e.g. a hip prosthesis, a scan of the forearm should be performed (Fig. 3). The radius provides information about cortical bone and should be the primary region of interest for patients with hyperparathyroidism [6].

\section{DXA Output}

The output from the DXA examination includes images of the body part scanned, quantitative data from the scanned area, including the bone mineral content (BMC), BMD, scanned area, $T$-scores, and $Z$-scores, and a graph of where the patient fits within the reference population.

The Images

\section{The Lumbar Spine}

The interpreting physician should check the scan for proper patient positioning and region of interest (ROI) placement. The spine should be aligned with the long axis of the scanner. The scan should include the inferior portion of T12 and the superior portion of L5. The DXA image shows the scanned regions from which the BMD measurement has been obtained (Fig. 4). There should be no focal areas of increased or reduced density within the regions of interest.

The figure includes labels showing numbering of the vertebrae. There is modest variability in the number of non-rib-bearing vertebrae and a transitional vertebra may be present at the lumbosacral junction. Approximately $85 \%$ of the population has five non rib-bearing lumbar vertebrae with four lumbar vertebrae in approximately $8 \%$ and six lumbar vertebrae in approximately $2 \%$ of the population [7]. The remainder of the population has other combinations of ribs and non rib-bearing vertebrae. For the purpose of vertebral numbering, a line drawn from the highest point of one iliac crest to the other iliac crest traverses the L4-L5 intervertebral disc space. If a lumbar spine radiograph is available, it may aid accurate numbering. The provider responsible for interpretation should check to ensure numbering of the vertebrae is correct. 


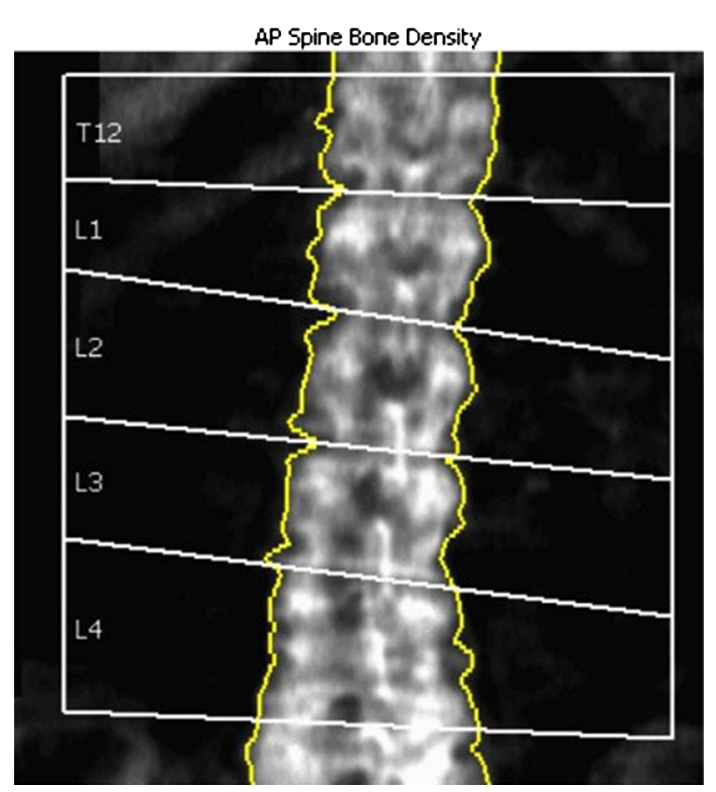

Fig. 4 DXA of the lumbar spine. Normal positioning. Initial DXA for pretreatment assessment of a 72-year-old woman with newly diagnosed breast carcinoma. In the posteroanterior view of the lumbar spine the lines through the disc spaces and the lines outlining the lateral margins of the vertebra demarcate the ROI. This patient has five lumbar vertebrae

Especially when a scan is being repeated, numbering of the vertebrae should be consistent.

\section{The Hip}

The interpreting physician should check the scan for proper patient positioning and ROI placement. The femur should be aligned with the long axis of the scanner and the lower extremity should be internally rotated (Fig. 5). The regions of interest (ROI) should be placed in accordance with the manufacturer recommendations. Irrespective of the manufacturer, the femoral neck region of interest may not include any ischium or greater trochanter. There should be no artifacts within the measured regions of interest.

\section{The Forearm}

The interpreting physician should check the scan for proper patient positioning and ROI placement. The forearm must be aligned with the long axis of the scanner. The ROIs should be placed in accordance with the manufacturer recommendations (Fig. 6). Scans with patient motion, previous fractures, orthopedic hardware, or other artifacts cannot be interpreted.

\section{Quantitative Information}

A table is provided with the BMD in $\mathrm{gm} / \mathrm{cm}^{2}$, the $T$-score and the $Z$-score (Fig. 7). The table displays each vertebra

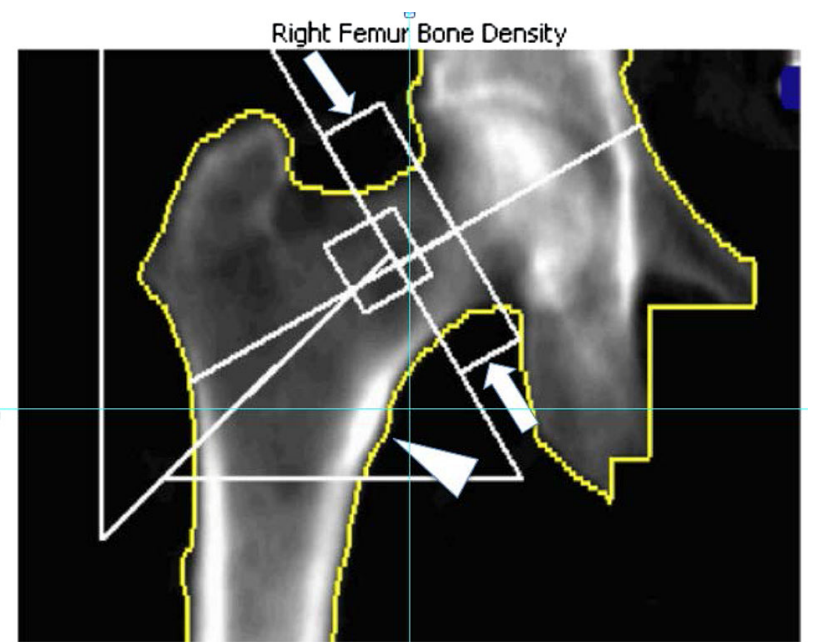

Fig. 5 DXA of the hip. Same patient as Fig. 4. The hip is in internal rotation to obtain a more en-face projection of the femoral neck. With internal rotation, the lesser trochanter is small or invisible (white arrowhead). Markup of the ROI varies with manufacturer. In this image, the total hip is indicated by the yellow outline of the bone margins, the superior margin of the femoral neck ROI, and the subtrochanteric horizontal line. The arrows indicate the femoral neck ROI. The femoral neck ROI varies with manufacturer but should not include the ilium or ischium (Color figure online)

individually and then combinations of vertebrae. The BMD should gradually increase from L1 to L4. For some patients, L4 will be less dense than L3. Nonetheless, each vertebra should be within one standard deviation of the next. If they are not, interpretation is not straightforward and the reader should refer to the section on complex interpretations.

In the most straightforward cases, the area included in the outlines of the four lumbar vertebrae is the region where the BMD is determined. This results in a BMD for an area that can be expressed as $\mathrm{gm} / \mathrm{cm}^{2}$. A $T$-score and $Z$-score are provided for the BMD at each location. The WHO definitions of normal, osteopenia, and osteoporosis are based on the DXA measurement of BMD [4]. To standardize among manufacturers and populations, the concepts of $T$-score and $Z$-score were introduced. Although $T$-scores are not strictly the same as standard deviations, for clinical purposes, they can be assumed to function the same way. Assuming a normally distributed population, if 0 is the mean, then a $T$-score of -1 is one standard deviation below the mean, a $T$-score of -2 is two standard deviations below the mean, etc. Sixty-eight percent of a normally distributed population sample falls within one standard deviation of the mean, $95 \%$ falls within two standard deviations, and $99.7 \%$ falls within three standard deviations of the mean [8]. To have a $T$-score of -2.5 , a patient must fall within the lowest two percent of the reference population. The reference population for the $T$-score consists of young asymptomatic subjects. The $Z$-score 

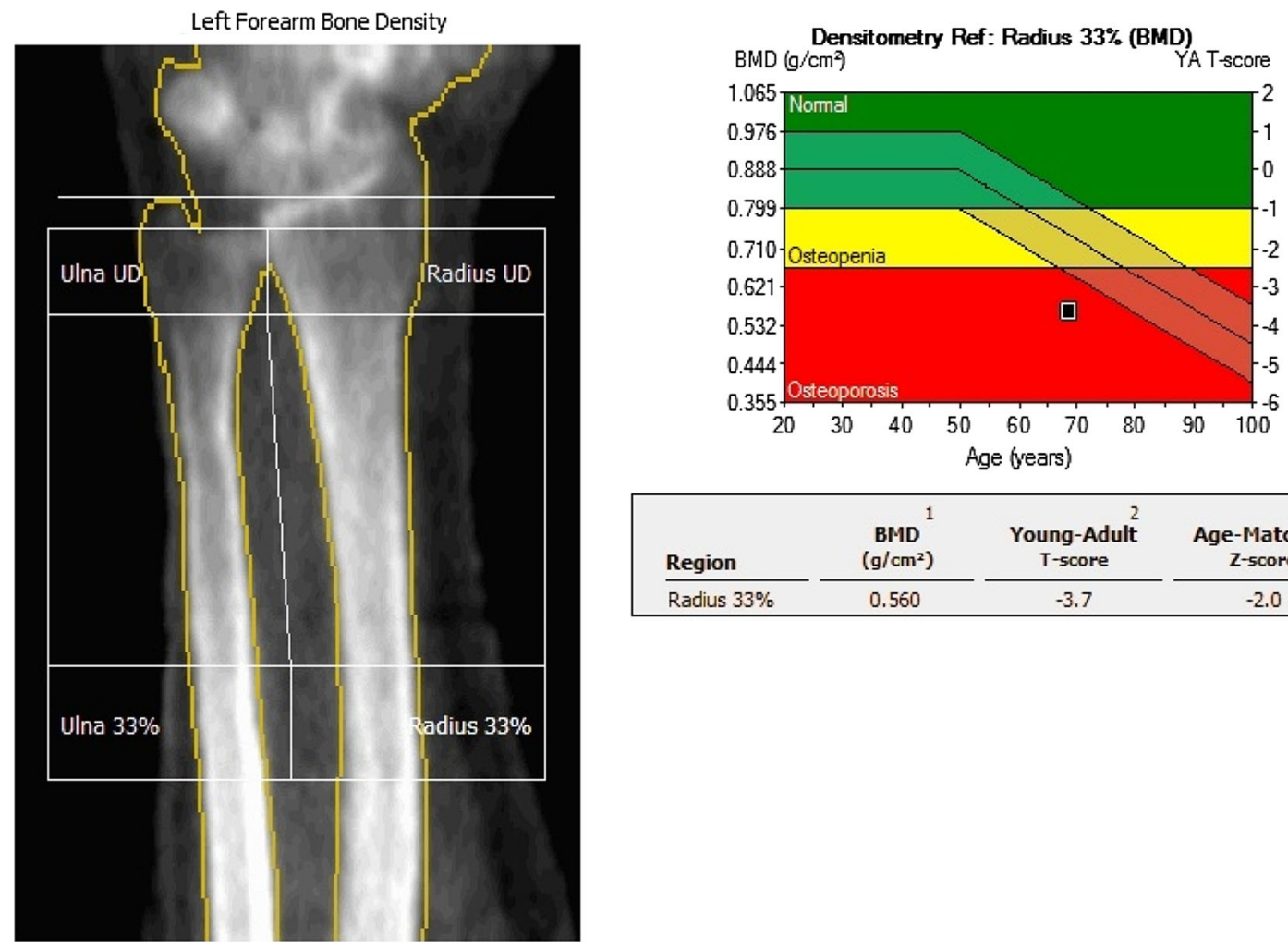

\begin{tabular}{|c|c|c|c|}
\hline Region & $\underset{\left(\mathrm{g} / \mathrm{cm}^{2}\right)}{\mathrm{BMD}^{1}}$ & $\underset{\text { T-score }}{\text { Young-Adult }}{ }^{2}$ & $\begin{array}{c}\text { Age-Matched } \\
\text { Z-score }\end{array}$ \\
\hline Radius $33 \%$ & 0.560 & -3.7 & -2.0 \\
\hline
\end{tabular}

Fig. 6 DXA of the forearm from another patient, a 68-year-old woman. The mid radius (33\%) $T$-score is -3.7 which is in the osteoporotic range. Note that the forearm is aligned with the long axis of the scanner

(a)

\begin{tabular}{|c|c|c|c|c|c|}
\hline Region & $\underset{\left(\mathrm{g} / \mathrm{cm}^{2}\right)}{\mathrm{BMD}}$ & $\begin{array}{l}\text { Young } \\
(\%)\end{array}$ & ${ }_{\text {-Adult }}{ }^{2}$ & $\begin{array}{l}\text { Age-1 } \\
(\%)\end{array}$ & $\begin{array}{c}\text { latched } \\
\text { Z-Score }\end{array}$ \\
\hline L1 & 1.108 & 97 & -0.3 & 111 & 0.9 \\
\hline L2 & 1.071 & 89 & -1.1 & 100 & 0.0 \\
\hline L3 & 1.197 & 98 & -0.2 & 111 & 1.0 \\
\hline L4 & 1.241 & 102 & 0.2 & 115 & 1.3 \\
\hline L1-L4 & 1.163 & 97 & -0.3 & 110 & 0.9 \\
\hline
\end{tabular}

\section{(b) ANCILLARY RESULTS [AP Spine]}

\begin{tabular}{|c|c|c|c|c|c|}
\hline \multirow[b]{2}{*}{ Region } & \multirow{2}{*}{$\underset{\left(g / \mathrm{cm}^{2}\right)}{\mathrm{BMD}}$} & \multicolumn{2}{|c|}{ Young-Adult ${ }^{2}$} & \multicolumn{2}{|c|}{ Age-Matched } \\
\hline & & $(\%)$ & T-Score & $(\%)$ & Z-Score \\
\hline$T 12$ & 0.964 & - & - & - & - \\
\hline L1 & 1.108 & 97 & -0.3 & 111 & 0.9 \\
\hline L2 & 1.071 & 89 & -1.1 & 100 & 0.0 \\
\hline L3 & 1.197 & 98 & -0.2 & 111 & 1.0 \\
\hline L4 & 1.241 & 102 & 0.2 & 115 & 1.3 \\
\hline L1-L2 & 1.089 & 93 & -0.7 & 105 & 0.4 \\
\hline L1-L3 & 1.127 & 95 & -0.5 & 108 & 0.7 \\
\hline L1-L4 & 1.163 & 97 & -0.3 & 110 & 0.9 \\
\hline L2-L3 & 1.135 & 94 & -0.6 & 106 & 0.5 \\
\hline L2-L4 & 1.179 & 97 & -0.3 & 110 & 0.8 \\
\hline
\end{tabular}

Fig. 7 Table of BMD, $T$-scores, and $Z$-scores. Same patient as Fig. 4. The table shows the bone mineral density in $\mathrm{gm} / \mathrm{cm}^{2}$, the $T$-score, and $Z$-scores for each region of interest of the spine. The DXA software calculates the BMC in the entire ROI and divides by the area of the ROI to calculate the BMD. Note that the information is presented for individual vertebrae and for the L1-L4 combination (a). The patient's data for four vertebrae is BMD $1.163 \mathrm{~g} / \mathrm{cm}^{2}$, the $T$-score is -0.3 and the $Z$-score is 0.9 . The vertebral information may also be presented for other combinations of fewer than four vertebrae (b)

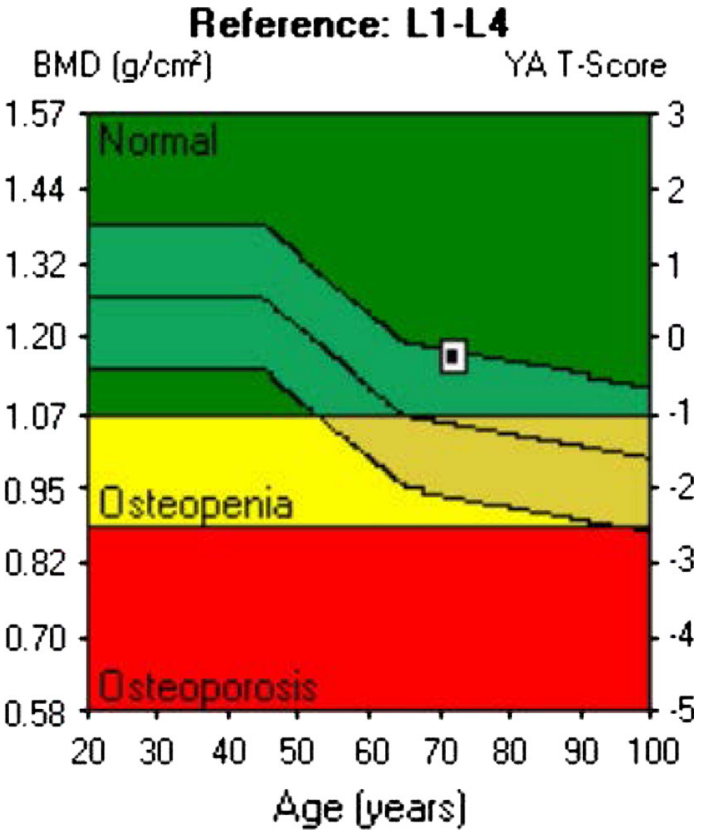

Fig. 8 The bone density graph. Same patient as Fig. 4. This graph shows the bone densities of the reference population with which the patient is being compared (central light green region). The bone densities for normal, osteopenia, and osteoporosis are superimposed on the graph. The location of the patient's vertebral bone density is shown on the graph (square dot in the box). A graph is also provided for the hip (not shown) (Color figure online) 


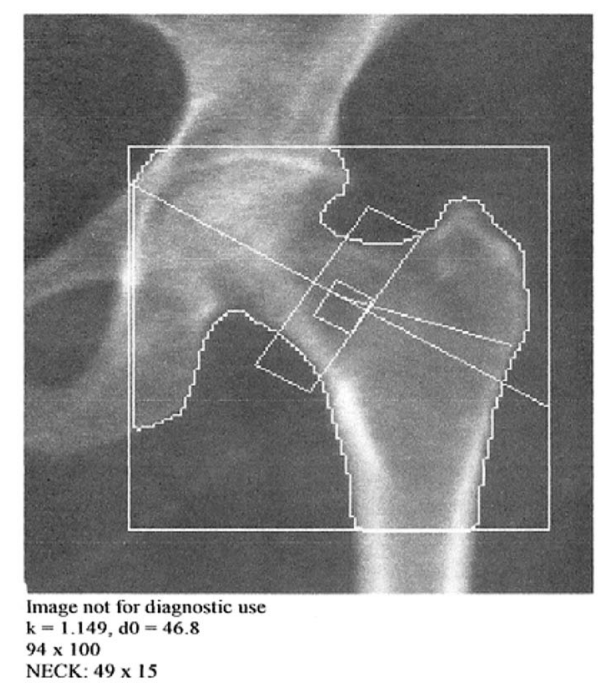

\section{Scan Information:}

Scan Date: February 29, 2012

Scan Type: a Left Hip

Analysis: February 29, 2012 14:17 Version 13.3:3

Hip

Model: $\quad$ Discovery A (S/N 70314)

Comment: FV3-

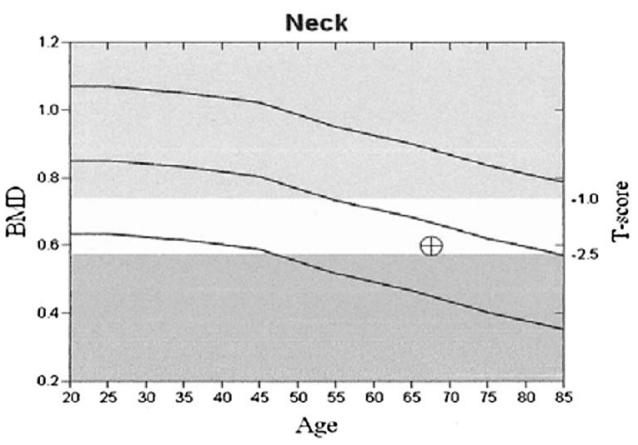

DXA Results Summary:

\begin{tabular}{|c|c|c|c|c|c|c|c|}
\hline Region & $\begin{array}{c}\text { Area } \\
\left(\mathbf{c m}^{2}\right)\end{array}$ & $\underset{(\mathrm{g})}{\text { BMC }}$ & $\underset{\left(\mathrm{g} / \mathrm{cm}^{2}\right)}{\mathbf{B M D}}$ & $\begin{array}{l}\text { T- } \\
\text { score }\end{array}$ & $\begin{array}{c}\text { PR } \\
(\%)\end{array}$ & $\begin{array}{c}\mathbf{Z}- \\
\text { score }\end{array}$ & $\underset{(\%)}{A M}$ \\
\hline Neck & 5.02 & 3.00 & 0.596 & -2.3 & 70 & -0.6 & 90 \\
\hline Troch & 9.72 & 6.03 & 0.621 & -0.8 & 88 & 0.4 & 107 \\
\hline Inter & 17.14 & 18.18 & 1.061 & -0.3 & 96 & 0.9 & 114 \\
\hline Total & 31.88 & 27.21 & 0.854 & -0.7 & 91 & 0.6 & 110 \\
\hline
\end{tabular}

Total BMD CV $1.0 \%, \mathrm{ACF}=1.025, \mathrm{BCF}=1.008, \mathrm{TH}=6.208$

WHO Classification: Osteopenia

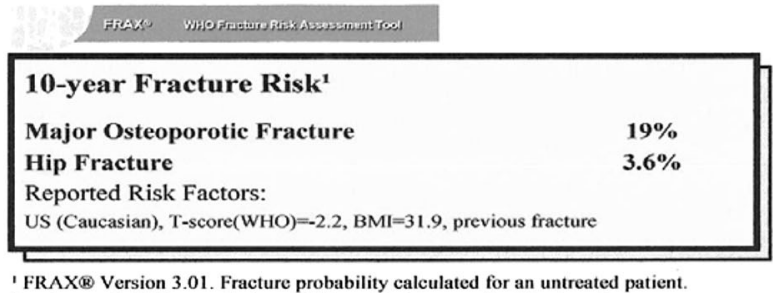

t. Fracture probability may be lower if the patient has received treatment.

\section{Comment:}

All treatment decisions require clinical judgment and consideration of individual patient factors, including patient preferences, comorbidities, previous drug use and risk factors not captured in the FRAX model (e.g. frailty, falls, vitamin $\mathrm{D}$ deficiency, increased bone turnover, interval significant decline in BMD).

Fig. 9 DXA of the hip. Sixty-seven-year-old woman with previous fracture of the distal radius. Femoral neck $T$-score is -2.3 , which is in the osteopenic range. This is an ideal patient for FRAX ${ }^{\circledR}$. Because the 10-year-risk of hip fracture exceeds $3 \%$, this patient meets the National Osteoporosis Foundation guidelines for pharmacologic therapy
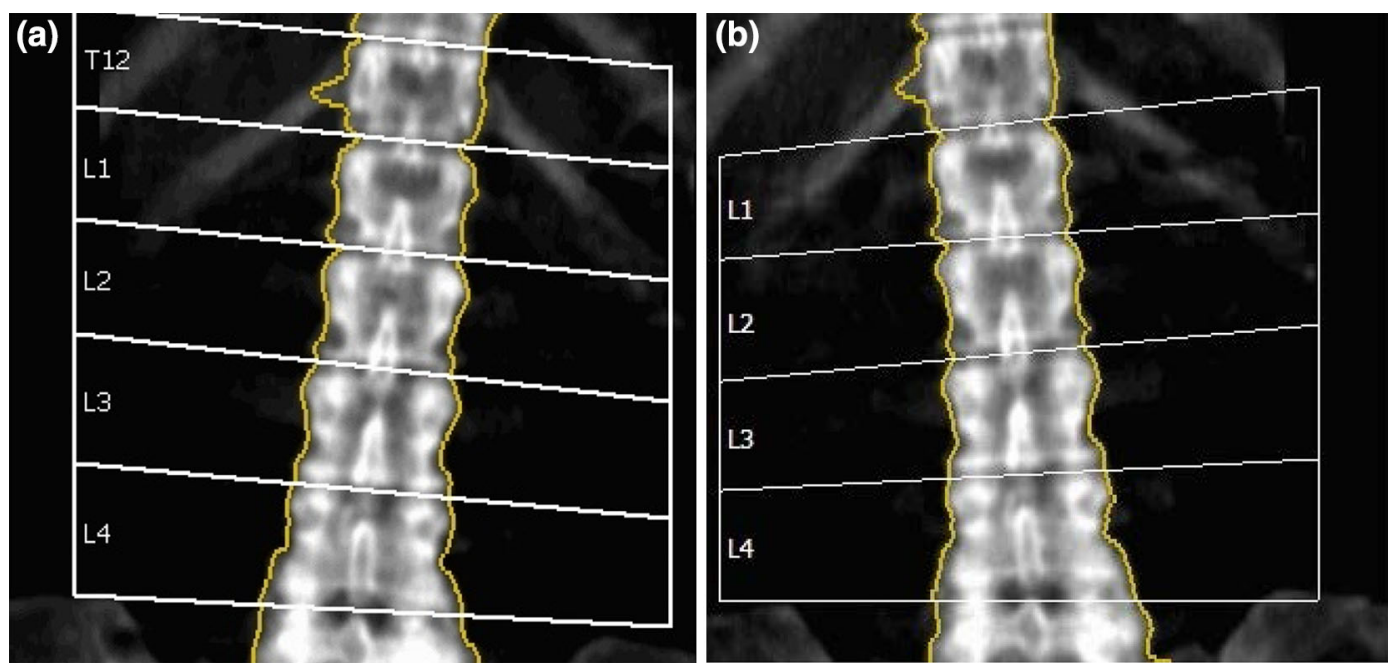

Fig. 10 DXA of the lumbar spine. Baseline and follow up scans obtained two years apart. The studies cannot be compared because of a marked change in patient positioning. The case emphasizes the need to have the spine aligned with the long axis of the scanner in all studies 

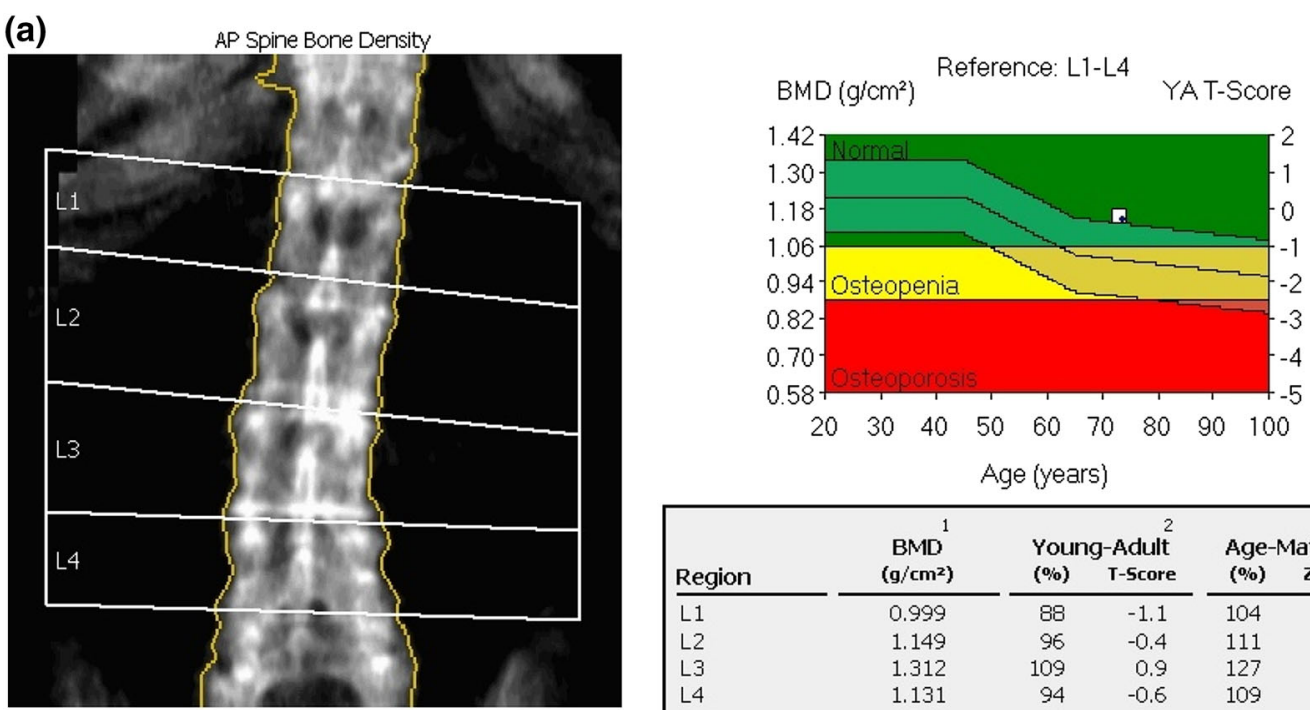

\begin{tabular}{|c|c|c|c|c|c|}
\hline Region & $\begin{array}{c}{ }^{1} \\
\left(\mathrm{~g} / \mathrm{cm}^{2}\right)\end{array}$ & \multicolumn{2}{|c|}{ Young-Adult ${ }^{2}$} & \multicolumn{2}{|c|}{ Age-Matched ${ }^{3}$} \\
\hline L1 & 0.999 & 88 & -1.1 & 104 & 0.3 \\
\hline L2 & 1.149 & 96 & -0.4 & 111 & 1.0 \\
\hline L3 & 1.312 & 109 & 0.9 & 127 & 2.3 \\
\hline L4 & 1.131 & 94 & -0.6 & 109 & 0.8 \\
\hline L1-L2 & 1.085 & 94 & -0.5 & 110 & 0.9 \\
\hline L1-L3 & 1.165 & 100 & 0.0 & 116 & 1.3 \\
\hline L1-L4 & 1.156 & 98 & -0.2 & 114 & 1.2 \\
\hline L2-L3 & 1.227 & 102 & 0.2 & 119 & 1.6 \\
\hline L2-L4 & 1.198 & 100 & 0.0 & 116 & 1.4 \\
\hline L3-L4 & 1.225 & 102 & 0.2 & 119 & 1.6 \\
\hline
\end{tabular}
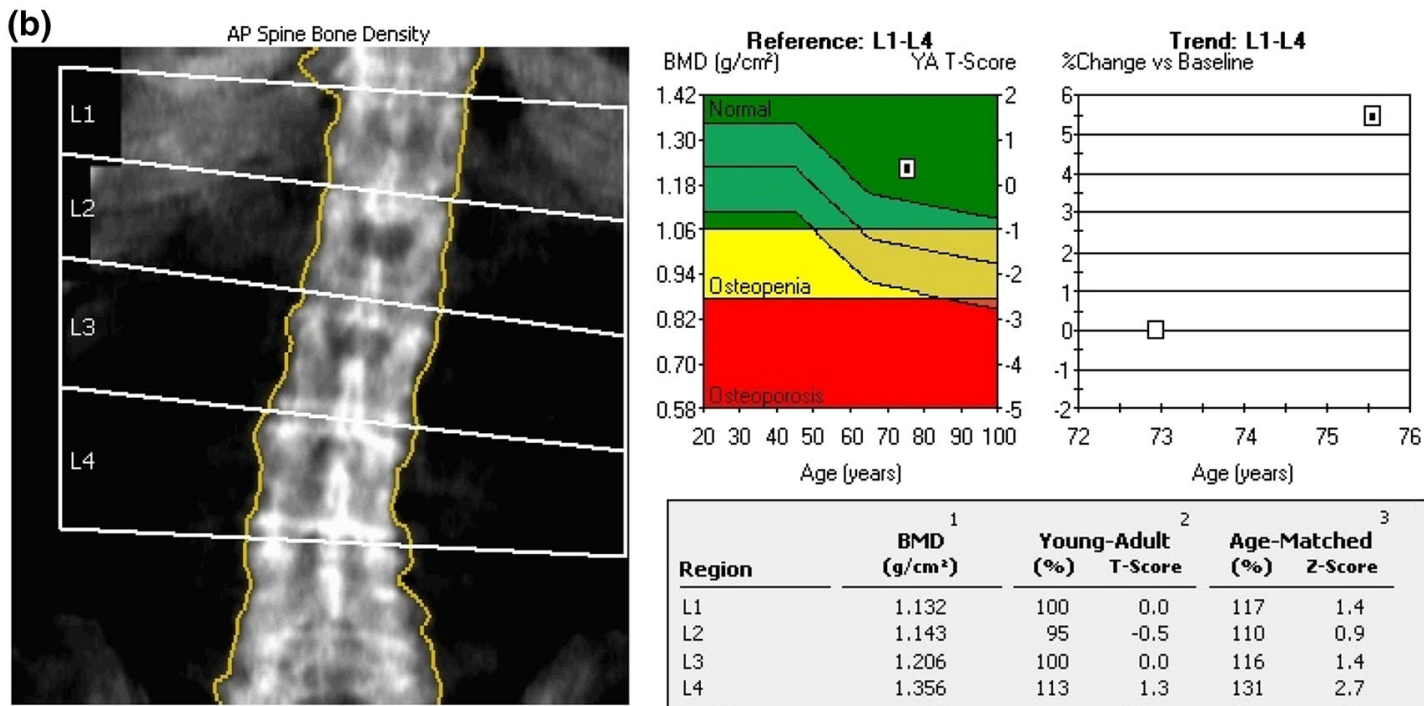

\begin{tabular}{|c|c|c|c|c|c|}
\hline Region & $\underset{\left(g / \mathrm{cm}^{2}\right)}{\mathrm{BMD}^{1}}$ & \multicolumn{2}{|c|}{$\begin{array}{l}\text { Young-Adult }{ }^{2} \\
(\%) \quad \text { T-Score }\end{array}$} & \multicolumn{2}{|c|}{ Age-Matched } \\
\hline L1 & 1.132 & 100 & 0.0 & 117 & 1.4 \\
\hline L2 & 1.143 & 95 & -0.5 & 110 & 0.9 \\
\hline L3 & 1.206 & 100 & 0.0 & 116 & 1.4 \\
\hline L4 & 1.356 & 113 & 1.3 & 131 & 2.7 \\
\hline L1-L2 & 1.138 & 99 & -0.1 & 115 & 1.3 \\
\hline L1-L3 & 1.164 & 99 & 0.0 & 116 & 1,3 \\
\hline L1-L4 & 1.220 & 103 & 0.3 & 120 & 1.7 \\
\hline L2-L3 & 1.177 & 98 & -0.2 & 114 & 1.2 \\
\hline L2-L4 & 1.243 & 104 & 0.4 & 120 & 1.7 \\
\hline L3-L4 & 1.283 & 107 & 0.7 & 124 & 2.1 \\
\hline
\end{tabular}

\begin{tabular}{|c|c|c|c|c|}
\hline \multirow[b]{2}{*}{$\begin{array}{l}\text { Measured } \\
\text { Date }\end{array}$} & \multicolumn{4}{|c|}{ Trend: L1-L4 } \\
\hline & $\begin{array}{c}\text { Age } \\
\text { (years) }\end{array}$ & $\underset{\left(\mathrm{g} / \mathrm{cm}^{2}\right)}{\mathrm{BMD}}$ & $\begin{array}{c}\text { Baseline } \\
(\%)\end{array}$ & $\begin{array}{c}\text { Baseline } \\
\text { (\%/yr) }\end{array}$ \\
\hline $6 / 4 / 2012$ & 75.5 & 1.220 & 5.5 & 2.1 \\
\hline $10 / 23 / 2009$ & 72.9 & 1.156 & baseline & baseline \\
\hline
\end{tabular}

Fig. 11 DXA of the lumbar spine. Baseline (a) and follow up (b, c) scans obtained three years apart for a patient receiving bisphosphonate therapy. In the initial analysis of the follow up scan (b) vertebral numbering is inconsistent. The BMD increase is assumed to be $5.5 \%$. Re-analysis of the follow up scan (c) with vertebral numbering corrected shows that the increase in BMD is actually $8.8 \%$. This is a very common pitfall of monitoring patients by use of DXA 

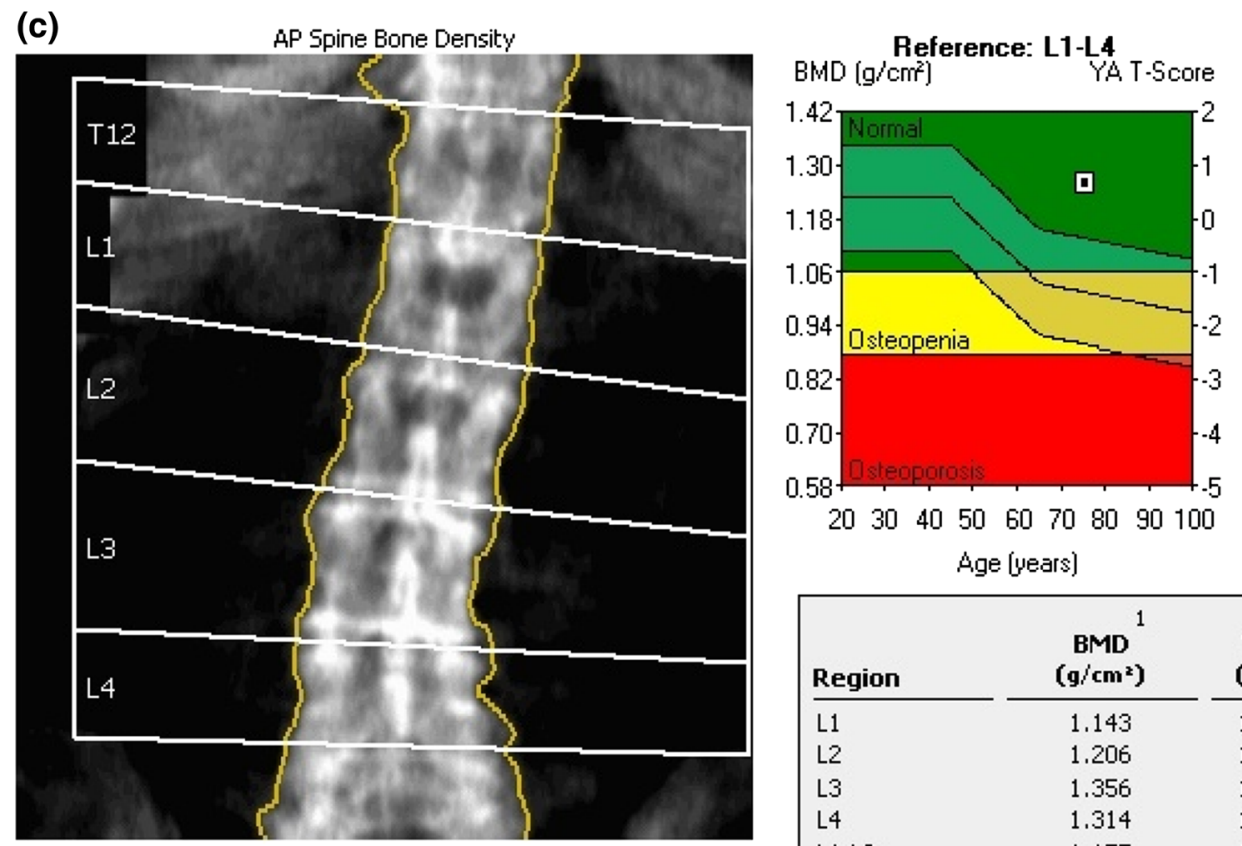

Trend: L1-L4

Change vs Baseline

\begin{tabular}{|c|c|c|c|c|c|}
\hline Region & $\underset{\left(\mathrm{g} / \mathrm{cm}^{2}\right)}{{ }^{1}}$ & $\begin{array}{l}\text { Young } \\
(\%)\end{array}$ & $\begin{array}{c}{ }^{2} \text {-Adult } \\
\text { T-Score }\end{array}$ & $\begin{array}{l}\text { Age- } \\
(\%)\end{array}$ & $\begin{array}{l}\text { latched }^{3} \\
\text { Z-score }\end{array}$ \\
\hline L1 & 1.143 & 101 & 0.1 & 118 & 1.5 \\
\hline L2 & 1.206 & 100 & 0.0 & 116 & 1.4 \\
\hline L3 & 1.356 & 113 & 1.3 & 131 & 2.7 \\
\hline L4 & 1.314 & 109 & 0.9 & 127 & 2.3 \\
\hline L1-L2 & 1.177 & 102 & 0.2 & 119 & 1.6 \\
\hline L1-L3 & 1.243 & 106 & 0.6 & 123 & 2.0 \\
\hline L1-L4 & 1.259 & 107 & 0.7 & 124 & 2.0 \\
\hline L2-L3 & 1.283 & 107 & 0.7 & 124 & 2.1 \\
\hline L2-L4 & 1.292 & 108 & 0.8 & 125 & 2.1 \\
\hline L3-L4 & 1.338 & 111 & 1.1 & 129 & 2.5 \\
\hline
\end{tabular}

COMMENTS:

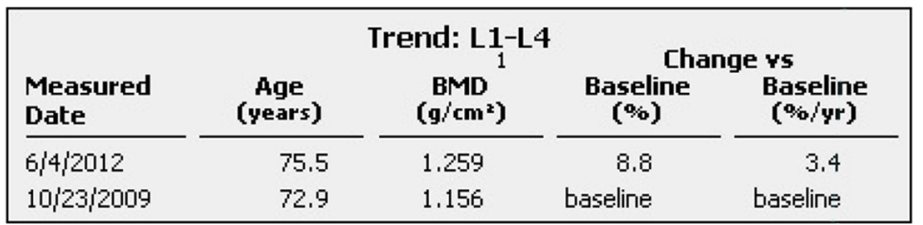

Fig. 11 continued

functions similarly to the $T$-score but compares the patient with a database of people of the same age. In the US, the International Society for Clinical Densitometry (ISCD) recommends using the Caucasian database for all patients [9].

Quantitative information is also provided for multiple ROIs in the hip including the femoral neck, trochanter, Ward's region, and total hip. A $T$-score and $Z$-score are provided for the BMD at each of these locations.

\section{The Graph}

A graph of the patient's BMD in relation to the reference population is provided (Fig. 8).

\section{Interpretation}

For diagnostic categorization, the region with the lowest $T$-score is identified from among the lumbar spine, hip, or radius. For the spine, the L1-L4 region is used unless focal artifacts require exclusion of individual vertebra. A single vertebra should not be used. For the hip, the lower $T$-score between the femoral neck and total hip is used. For the forearm, the mid third radius (also called $33 \%$ or $1 / 3$ ) is used. The patient is normal if the BMD results in a $T$-score equal to or greater than -1 . If the BMD results in a $T$-score equal to or below -2.5 , the patient has osteoporosis. Finally, if the patient's BMD results in a $T$-score below -1.0 and above -2.5 , the patient is placed in a middle category, originally called osteopenia. The ISCD currently recommends that this category be called "low bone mineral density". As an example, our reports state, in a straightforward way, "The lowest $T$-score occurs at the left femoral neck and is in the range designated osteoporosis".

In addition to providing a diagnosis, DXA examinations enable estimation of the patient's risk of subsequent fracture. The most commonly used method for assessment of fracture risk is the FRAX ${ }^{\circledR}$ tool developed for the World Health Organization. On the basis of femoral neck BMD in $\mathrm{gm} / \mathrm{cm}^{2}$ and clinical risk factors, the tool calculates a 

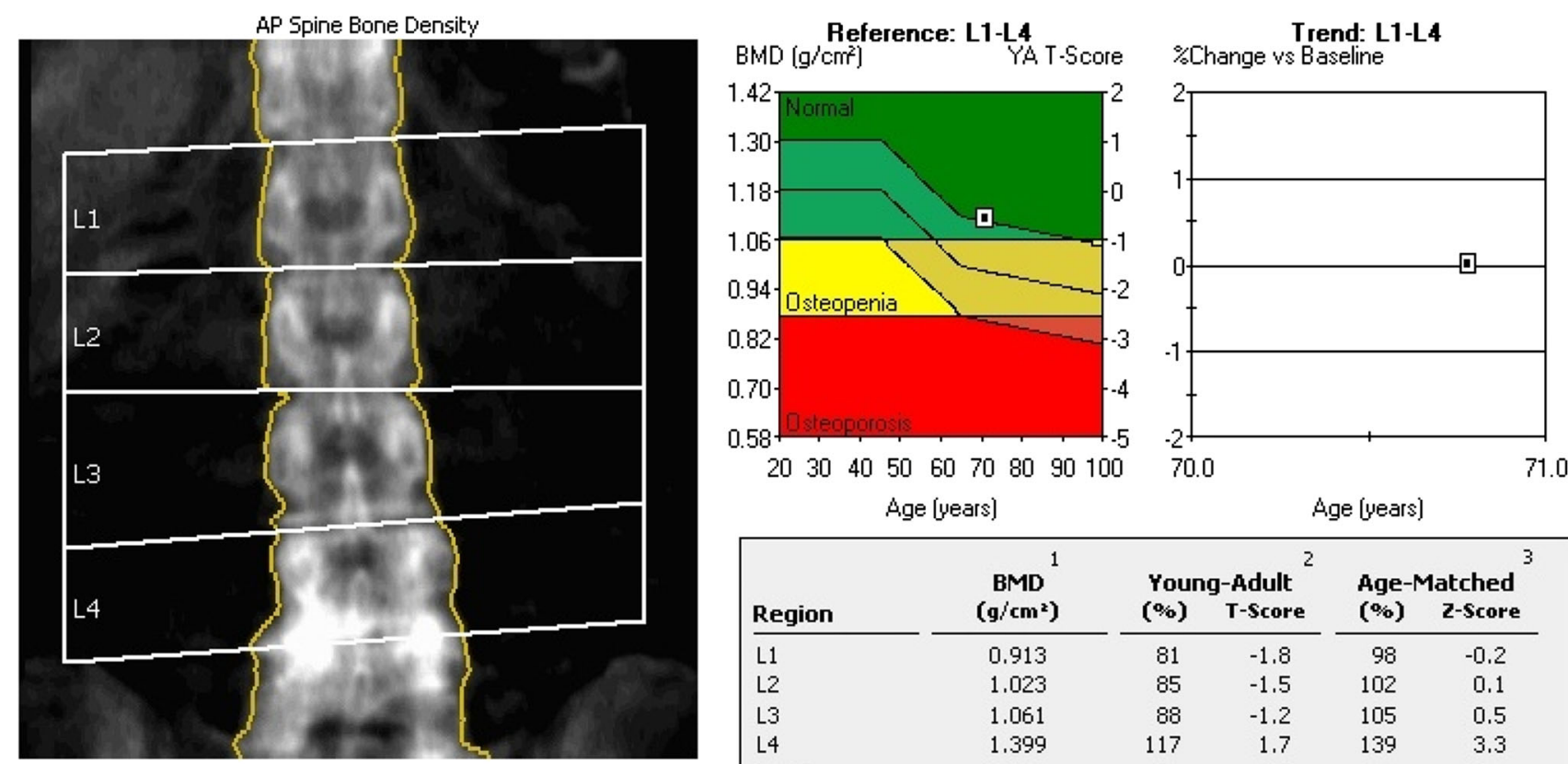

\begin{tabular}{|c|c|c|c|c|c|}
\hline Region & $\mathrm{BMD}^{1}$ & \multicolumn{2}{|c|}{ Young-Adult $^{2}$} & \multicolumn{2}{|c|}{ Age-Matched } \\
\hline L1 & 0.913 & 81 & -1.8 & 98 & -0.2 \\
\hline L2 & 1.023 & 85 & -1.5 & 102 & 0.1 \\
\hline L3 & 1.061 & 68 & -1.2 & 105 & 0.5 \\
\hline L4 & 1.399 & 117 & 1.7 & 139 & 3.3 \\
\hline $\mathrm{L} 1-\mathrm{L} 2$ & 0.968 & 84 & -1.5 & 101 & 0.1 \\
\hline L1-L3 & 1.003 & 86 & -1.4 & 103 & 0.2 \\
\hline L1-L4 & 1.110 & 94 & -0.6 & 113 & 1.0 \\
\hline L2-L3 & 1.044 & 87 & -1.3 & 104 & 0.3 \\
\hline L2-L4 & 1.169 & 97 & -0.3 & 116 & 1.4 \\
\hline L3-L4 & 1.231 & 103 & 0.3 & 122 & 1.9 \\
\hline
\end{tabular}

Fig. 12 DXA of the lumbar spine of a 70-year-old woman. The image shows sclerosis of L4. There is large discrepancy between $T$-scores at L4 (1.7) and L3 (-1.2). L4 must be excluded from the

ten-year probability of experiencing a hip fracture and a ten-year probability of experiencing what it terms "major osteoporotic fracture". Major osteoporotic fracture includes fractures involving the proximal femur, spine, proximal humerus, or distal radius. In the United States, the National Osteoporosis Foundation and the ISCD recommend limiting the use of the FRAX ${ }^{\circledR}$ tool to patients over age 50, who are not receiving pharmacologic therapy, who have not had hip or spine fracture, and who have DXAmeasured BMD in the osteopenic range (Fig. 9).

Additional items may be added to the DXA report to assist in management of the patient. These include a suggestion to evaluate patients for causes of secondary osteoporosis or osteomalacia, a recommendation for treatment initiation, and a recommendation for the next follow up DXA. Inclusion of these recommendations depends on the provider referral base. These recommendations may be more helpful if the referring provider is less familiar with management of osteoporosis than if $\mathrm{s} / \mathrm{he}$ is an expert in its management.

For premenopausal women and men younger than 50 years, the WHO criteria should not be used. For these groups diagnosis is based on the $Z$-score. Patients with $Z$-scores below -2 are categorized as "low bone density for age". analysis. The L1-L3 $T$-score is -1.3 , resulting in diagnosis of osteopenia. Had L4 not been excluded, the patient would have been erroneously diagnosed as normal

It is important to recognize that a clinical diagnosis of osteoporosis may be made for patients with fragility fractures, irrespective of their BMD measurement.

\section{The Mildly Complex Examination}

Follow up of Previous Evaluation

Patients frequently undergo repeated examination to monitor decreases in BMD or to evaluate the effects of treatment. When this occurs, a DXA examination becomes somewhat more complex. Physiologically, bone turnover is relatively slow and changes in BMD over time may be small. To detect these small changes, the normal variance of the test must be known. The provider of DXA services should develop a quality-assurance program that can demonstrate that the BMD measurements fall within accepted ranges.

There are two parts of such a program. The first involves in-vitro testing with a phantom of known densities, which ensures the scanner is operating within established limits. Scanners should be recalibrated if they cannot reproduce results within $1 \%$. This testing should be performed on a weekly basis and a log of the results maintained. 
(a)

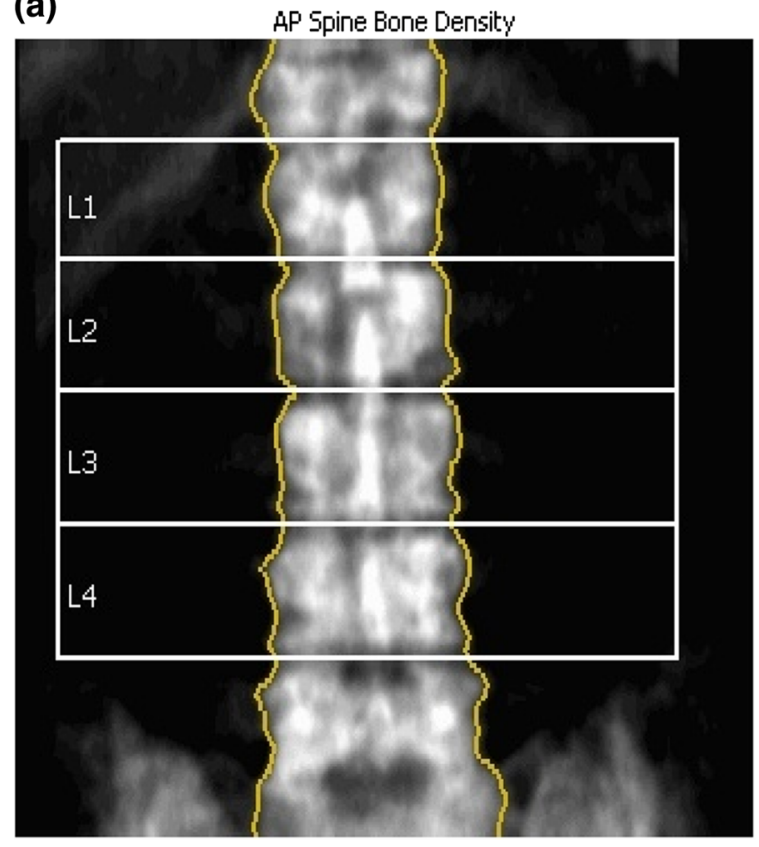

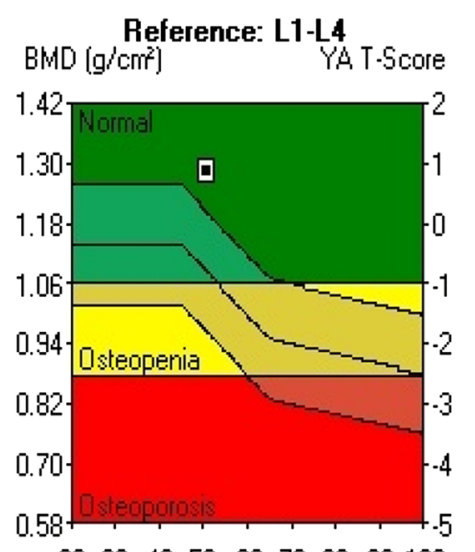

$20304050 \quad 6070 \quad 8090100$ Age (years)

\begin{tabular}{|c|c|c|c|c|c|}
\hline Region & $\mathrm{BMD}^{1}$ & \multicolumn{2}{|c|}{ Young-Adult $^{2}$} & \multicolumn{2}{|c|}{ Age-Matched } \\
\hline L1 & 1.257 & 111 & 1.1 & 122 & 1.9 \\
\hline L2 & 1.229 & 102 & 0.2 & 111 & 1.0 \\
\hline L3 & 1.332 & 111 & 1.1 & 121 & 1.9 \\
\hline L4 & 1.306 & 109 & 0.9 & 118 & 1.7 \\
\hline L1-L2 & 1.243 & 108 & 0.8 & 118 & 1.6 \\
\hline L1-L3 & 1.275 & 109 & 0.9 & 119 & 1.7 \\
\hline L1-L4 & 1.284 & 109 & 0.9 & 118 & 1.7 \\
\hline L2-L3 & 1.283 & 107 & 0.7 & 116 & 1.5 \\
\hline L2-L4 & 1.291 & 108 & 0.8 & 117 & 1.6 \\
\hline L3-L4 & 1.319 & 110 & 1.0 & 119 & 1.8 \\
\hline
\end{tabular}

Trend: L1-L4

*Change vs Baseline

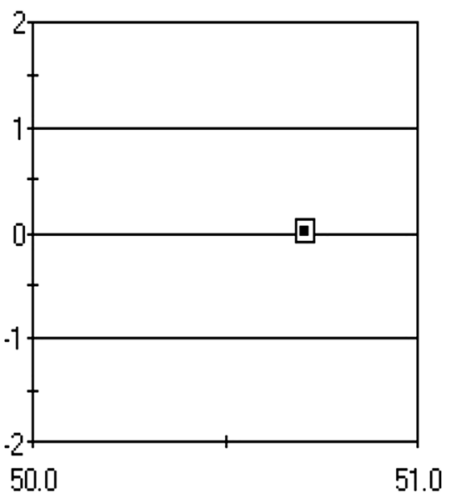

Age (years)

(b)

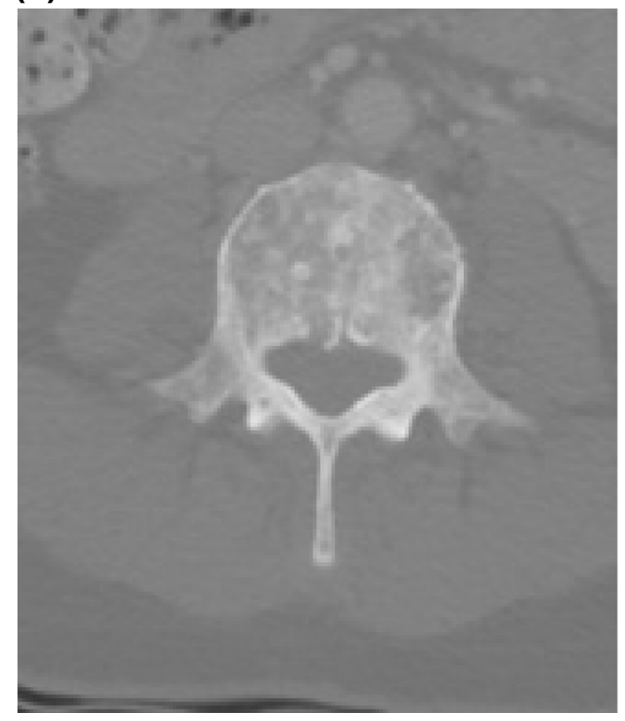

Fig. 13 DXA of the lumbar spine of a 51-year-old woman. The DXA image shows patchy sclerosis in all visualized vertebra. CT images show diffuse metastasis from breast carcinoma

The second type of assessment is an in-vivo evaluation of the combined performance of the scanner and the technician. Because the output of the scanner depends on 
Fig. 14 Increased bone mineral density because of vertebral fracture with collapse. Seventyfive-year-old man with fall 11 months earlier. L2 has increased density on the DXA image (plus symbols) (a). The vertebra shows collapse with sclerosis from the healing fracture $(\mathbf{b})$ (a)

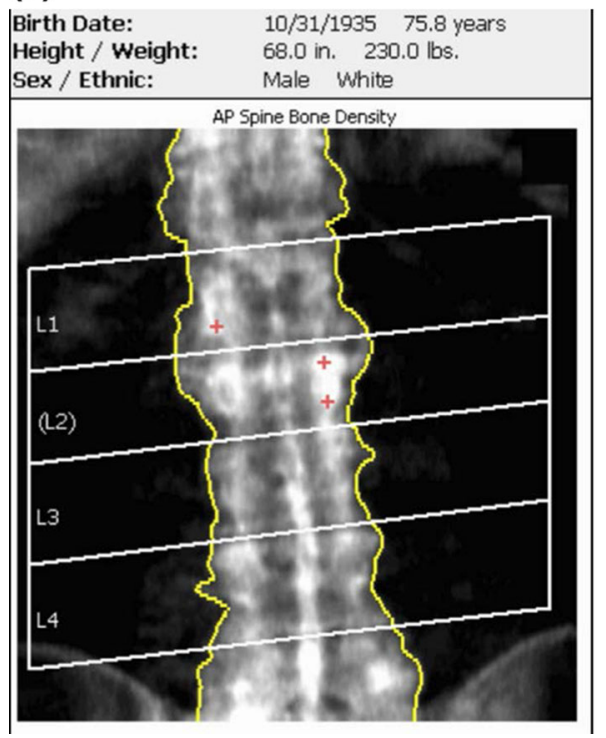

(b)

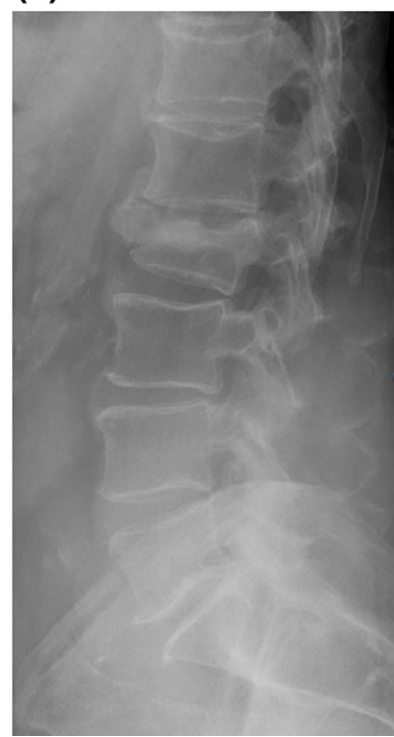

error expected in the test as a result of inherent machine fluctuations plus the imperfections due to the technologist's positioning of the patient and selection of the ROIs. According to the ISCD, the minimum acceptable precision is $1.9 \%$ at the lumbar spine, $1.8 \%$ at the total hip, and $2.5 \%$ at the femoral neck. For facilities with multiple technicians, the PE may be calculated using combined information from the group. The LSC is the PE multiplied by the factor required to encompass the $95 \%$ confidence interval, which is 2.77. The approach for determining precision error has been standardized by the ISCD $[10,11]$.

DXA scanners from different manufacturers vary in the method of BMD measurement. Also, different DXA scanners from the same manufacturer may vary slightly in how BMD is measured. Because of this variance, it is not possible to make straightforward comparisons for patients examined at different facilities. Ideally, follow-up testing should be performed on the same machine with the same technician. Listings of the assumed quality of information have been suggested. In descending order of information quality, these include: same machine, same technician; same machine, different technician; different machine within the same enterprise (with machines cross calibrated), same technician; different machine within the same enterprise (with machines cross calibrated), different technician. For follow-up reports, the item of interest is the actual BMD and not the $T$-score. When a change in BMD exceeds the center's LSC, this is a statistically significant change that should be included in the report. If a previous report is available for an examination performed at a different facility, the interpreting provider for the current examination should state that any degree of BMD change between the two facilities is uncertain.
When monitoring patients using DXA, it is very important to check the DXA images for consistent patient positioning and scan analysis. If patient position is not consistent (Fig. 10) comparison cannot be performed. If vertebral numbering is inconsistent (Fig. 11), the vertebra must be renumbered.

\section{The Complex Examination}

Although most DXA examinations are straightforward or mildly complex, a modest number are more complex. All of the principles described above must be applied to these cases. For some patients there may be ROI that cannot be evaluated. Common reasons include increased density from osteophytes or osteoarthritis, scoliosis, and compression fractures. In addition, previous intervention may produce areas of increased density from vertebroplasty, posterior spinal instrumentation with or without bone grafting, previous hip surgery with pins or screws, and previous hip arthroplasty.

\section{Exclusion of Vertebrae}

If there are no focal structural abnormalities (described above), the first four lumbar vertebrae should be included in the spine evaluation. These vertebrae should have BMDs within $1 \mathrm{SD}$ of each other. If they do not, and the image shows focal increased or reduced attenuation, the abnormal vertebra should be excluded. The printout provides common combinations of fewer than four vertebrae that may be used to determine the BMD, $T$-score, and $Z$-score. Interpretations of the lumbar spine should always include at least two vertebrae (Fig. 12). 
As patients age, they commonly develop degenerative disc disease of the spine and scoliosis. In these instances, there is an artifactual increase in BMD and the entire spine should be excluded (Fig. 13). In such circumstances the technician should add a forearm scan.

\section{Large Change in BMD}

The change in the patient's BMD may be too large for agerelated osteoporosis. For example, a decrease of greater than $5 \%$ per year would be an unexpected change for agerelated osteoporosis. Conversely, with treatment, increases greater than $10 \%$ are unusual. If a patient's decrease in BMD is too large, the decrease may result from an error in measurement or a pathologic process. If measurement errors are excluded, lytic metastasis should be considered. Conversely, increased BMD could result from a blastic metastasis (Fig. 13), vertebral fracture with collapse (Fig. 14), or Paget's disease.

\section{Conclusion}

Dual energy X-ray absorptiometry is commonly used to assess bone mineral density. Although, superficially, machines' output seems straightforward and easy to interpret, several pitfalls can lead to misinterpretation. We have provided a basic approach that the interpreting provider can use to minimize these pitfalls and produce a clinically relevant report.

\section{Compliance with Ethics Guidelines}

Conflict of Interest RH Choplin, L Lenchik and S Wuertzer declares no conflicts of interest.
Human and Animal Rights and Informed Consent This article does not contain any studies with human or animal subjects performed by any of the authors.

\section{References}

1. U.S. Department of Health and Human Services. Bone health and osteoporosis: A report of the surgeon general. Rockville, MD: U.S. Department of Health and Human Services, Office of the Surgeon General, 2004. http://www.surgeongeneral.gov/library. Accessed February 2014.

2. Center JR, Bliuc D, Nguyen TV, Eisman JA. Risk of subsequent fracture after low-trauma fracture in men and women. JAMA. 2007;297:387-94.

3. Burge R, Dawson-Hughes B, Solomon DH, Wong JB, King A, Tosteson A. Incidence and economic burden of osteoporosisrelated fractures in the United States, 2005-2025. J Bone Miner Res. 2007;22:465-75.

4. Kanis JA, Melton LJ III, Christiansen C, Johnston CC, Khaltaev N. The diagnosis of osteoporosis. J Bone Miner Res. 1994;9: 1137-41.

5. Kanis JA, Johnell O, Oden A, Johansson H, McCloskey E. FRAX and the assessment of fracture probability in men and women from the UK. Osteoporos Int. 2008;19:385-97.

6. Wood K, Dhital S, Chen H, Sippel R. What is the utility of distal forearm DXA in primary hyperparathyroidism? Oncologist. 2012;17:322-5.

7. Peel NF, Johnson A, Barrington NA, Smith TW, Eastell R. Impact of anomalous vertebral segmentation on measurements of bone mineral density. J Bone Miner Res. 1993;8:719-23.

8. Bonnick SL. A statistical overview for the non-statistician densitometrist. Bone densitometry in clinical practice: application and interpretation. New York: Humana; 2010. p. 79-104.

9. ISCD Official Positions. http://www.iscd.org/official-positions/ 2013-iscd-official-positions-adult/. Accessed February 2014.

10. Bonnick SL. Monitoring change in bone density. Bone densitometry in clinical practice: application and interpretation. New York: Humana; 2010. p. 257-78.

11. ISCD Resources Calculators. http://www.iscd.org/resources/ calculators/ Accessed February 2014. 